\title{
G5 - Mapeamento de Instituições Acadêmicas, Empresas e Produtos em Plataformas Vegetais
}

Daniel A. Ribeiro ${ }^{1 *}$; Rosane C. Guimarães ${ }^{1}$; Denise C. S. Matos ${ }^{1}$; Júlio Cesar S. Rosa $^{1}$; Diana P.B. Freire ${ }^{1}$; Gisele C. Miranda ${ }^{1}$.

1 - Bio-Manguinhos/Fiocruz

\section{Introdução:}

A maioria dos biofármacos e vacinas disponíveis atualmente é produzida em células de mamíferos, insetos, ou células microbianas. Contudo, a produção em plataformas vegetais (expressão em plantas ou em células) possui algumas vantagens em relação aos sistemas convencionais: não abrigam patógenos humanos, e geralmente são processos mais baratos de operar e escalonar, devido à natureza robusta e exigências mais simples em relação às condições de cultura.

Bio-Manguinhos, de forma inovadora, pretende incorporar a tecnologia de produção em plataformas vegetais através de alianças estratégicas: um acordo de co-desenvolvimento de uma vacina de subunidade para Febre Amarela; e um acordo de transferência de tecnologia do biofármaco alfataliglucerase. Estas duas plataformas serão implantadas em um novo campus que será construído em Eusébio-CE. Este novo campus, escopo do Projeto Bio-Ceará, consiste na instalação de plantas de produção de proteínas recombinantes em folhas de tabaco e em células vegetais, além de um prédio de desenvolvimento tecnológico em plataformas vegetais.

Visando agregar conhecimento sobre o tema e aproximar instituições que possam colaborar com Bio-Manguinhos, foi criada, em 2014, a Comunidade de Prática de Plataformas Vegetais (CoP-PVEG). A CoP-PVEG consiste em discussões periódicas sobre as plataformas vegetais, palestras de profissionais da área, visitas técnicas. A possibilidade de formação de redes de colaboração a partir de iniciativas da CoP-PVEG incentivou a produção deste trabalho.

\section{Objetivo:}

O objetivo do trabalho consiste em identificar e mapear as instituições acadêmicas e empresas que trabalham em plataformas vegetais e quais produtos estão em fase de desenvolvimento. 


\section{Metodologia:}

Para a identificação dos principais centros acadêmicos foi realizada uma pesquisa bibliográfica em artigos científicos em base de dados como, "ISI Web of Knowledge"; Scopus, Scirus, "Web of Science" "Carrot 2", através do uso das seguintes palavras chaves: "Molecular Pharming" "Plant Made Pharmaceuticals", "Plant Made Drugs", "Plant Made Biologicals". Também foi consultado o website do Congresso Plant-Based Vaccines and Antibodies dos anos de 2013/2015. Para a identificação das empresas distribuídas pelo mundo e produtos em fase de desenvolvimento, além da busca por artigos científicos foram realizadas pesquisas nos sites das empresas e no site https://clinicaltrials.gov e também análise de comunicações pessoais das empresas.

\section{Resultados:}

Após o levantamento de dados, a equipe criou tabelas onde foram mapeados os alvos, a tecnologia empregada, a fase de desenvolvimento, os principais autores e instituições e os países de origem. As informações foram organizadas e discutidas em termos de relevância em reuniões periódicas. Foram elencados os principais centros de pesquisa, universidades e empresas a nível nacional e internacional que podem possuir ou já possuem relação de colaboração com Bio-Manguinhos, sendo os dados apresentados em forma de mapas de rede e tabelas.

\section{Conclusão:}

Esse mapeamento será importante para a identificação de alianças estratégicas em potencial para introdução de novos produtos nestas plataformas.

Palavras-Chave: Plataformas Vegetais; Mapeamento de redes 